\title{
GMO debate: inconclusive
}

\section{Krishna Dronamraju*}

Foundation for Genetic Research, Houston, TX, USA

*Correspndence: kdronamraj@aol.com

\section{Edited by:}

Richard A. Jorgensen, University of Arizona, USA
In his Foreword to my book Haldane's Daedalus Revisited, Nobel laureate Joshua Lederberg (1995) correctly emphasized the difficulty of making accurate scientific predictions. Nevertheless, I agree with M. S. Swaminathan (2012) that the current concerns of biosafety will soon give way to an appreciation of the potential benefits of the new genetics including the GMO technology. I have reviewed the subject of GMOs in agriculture in my book: "Emerging Consequences of Biotechnology" (2009).

A recent debate in Science (3 May, 2013) highlighted the views of the two opposing groups with respect to the desirability of introducing GM food crops in India. Two eminent scientists, P. M. Bhargava and G. Padmanaban, argued opposing and favoring GM crops, respectively. They were discussing, in particular, the moratorium imposed by India's Minister for environment and forests Jairam Ramesh in February 2010 on the cultivation of GM eggplant. Bhargava supported the indefinite moratorium which he termed "perfectly justified," whereas Padmanaban considered it "very unfortunate" because that decision was more populistic than science-based. Bhargava pointed out that there is a close association between the consumption of GM food and increased incidence of allergies, childhood cancers, and gastrointestinal disorders amongst Americans during the last several years.

Monsanto obtained crude data on the impact of feeding transgenic corn MON 863 for one mammalian species, instead of the three used for evaluations of pesticides or drugs. This study was first classified as confidential by the Company (2002). The data was then used to obtain commercial release agreements all over the world. After heated discussions in Europe concerning the possible physiological effects provoked by this
GMO, a decision in the German Appeal Court allowed public access to the crude data in June 2005. Monsanto then published its own interpretation of the data (Hammond et al., 2006) in which it was concluded that the MON 863 was safe to eat.

However, after careful analysis of the crude data, Seralini et al. (2007, 2009) applied appropriate statistical methodology to test the effects of the Bt maize on mammalian health. First, GM fed rats were compared to their closest isogenic controls, and then to the six reference groups which were fed various other maize-based diets that Monsanto added in the study. Data were compiled by organ, dose and timing of dietary exposure. In addition, the effects on the rat metabolism of the diet composition without GM maize was studied, comparing only control and reference groups between them to avoid systematically linking these effects to the GM diet. Monsanto did not conduct such a statistical study (Hammond et al., 2006). It is important to note that in order to isolate the effect of the GM transformation process from other variables it is only valid if we compare the GMO (in this case MON 863) with its isogenic non-GM equivalent. The inclusion in the analysis of unrelated feeding groups serves to confuse rather than clarify the effect of the MON 863.

After the consumption of MON863, rats showed slight but dose-related significant variations in growth for both sexes, resulting in $3.3 \%$ decrease in weight for males and $3.7 \%$ increase for females. Chemical measurements revealed signs of hepatorenal toxicity, marked also by differential sensitivities in males and females. Triglycerides increased by $24-40 \%$ in females (either at week 14, dose $11 \%$ or at week 5 , dose $33 \%$, respectively); urine phosphorus and sodium excretions diminished in males by $31-35 \%$ (week
14, dose 33\%). Long-term experiments are essential in order to establish the real nature and extent of the possible pathology. Present data cannot support the conclusion that GM corn MON 863 is a safe product.

The goal of the statistical analysis is to decide whether the consumption of GMOs can be considered to have no effect. This most important issue is totally overlooked in the experimental design and the statistical report made by Monsanto on MON 863. Moreover, any hypothesis which is not statistically significant with their reductive method is always excluded. This disturbing oversight runs false negative results and a risk of health consequences for millions of people and animals. Health risk assessment of genetically modified organisms (GMOs) cultivated for food or feed is under debate throughout the world, and very little data have been published on mid- or long-term toxicological studies with mammals.

\section{ACKNOWLEDGMENTS}

I thank Prof. M. S. Swaminathan and Ms. Michele Wambaugh for helpful comments.

\section{REFERENCES}

Alberts, B. (2013). Science news and analysis. Science 340, 539-540.

Dronamraju, K. R. (1995). Haldane's Daedalus Revisited. Oxford: Oxford University Press.

Dronamraju, K. R. (2009). Emerging Consequences of Biotechnology. New Jersey, NJ: World Scientific Publishing Co.

Hammond, B., Lemen, J., Dudek, R., Ward, D. Jiang, C., Nemeth, M., et al. (2006). Results of a 90-day safety assurance study with rats fed grain from corn rootworm-protected corn. Food Chem. Toxicol. 44, 147-160. doi: 10.1016/j.fct. 2005.06.008

Lederberg, J. (1995). "Foreword," in Haldane's Daedalus Revisited, ed K. R. Dronamraju, (Oxford: Oxford University Press), vii-ix.

Seralini, G-E., Cellier, D., and de Vendemois, J. S. (2007). New analysis of a rat feeding study with a 
genetically modified maize reveals signs of hepatorenal toxicity. Arch. Environ. Contam. Toxicol. 52, 596-602. doi: 10.1007/s00244-006-0149-5

Seralini, G-E., de Vendemois, J. S., Cellier, D., Sultan, C., Buiatti, M., Gallagher, L., et al. (2009). How subchronic and chronic health effects can be neglected for GMOs, pesticides or chemicals. Int. J. Biol. Sci. 5, 438-443. doi: 10.7150/ijbs. 5.438
Swaminathan, M. S. (2012). This I believe: agricultural science and genetics. Front. Genet. 3:282. doi: 10.3389/fgene.2012.00282

Received: 22 May 2013; accepted: 06 June 2013; published online: 01 July 2013.

Citation: Dronamraju K (2013) GMO debate: inconclusive. Front. Genet. 4:123. doi: 10.3389/fgene.2013.00123
This article was submitted to Frontiers in Plant Genetics and Genomics, a specialty of Frontiers in Genetics.

Copyright (C) 2013 Dronamraju. This is an openaccess article distributed under the terms of the Creative Commons Attribution License, which permits use, distribution and reproduction in other forums, provided the original authors and source are credited and subject to any copyright notices concerning any third-party graphics etc. 